\title{
Equipment of the Aeromobile Group of the Main Department of the Emercom of Russia in the Republic of Karelia
}

\author{
Khoroshilov K. ${ }^{1}$, Pashkova A. ${ }^{2}$, Zaitsev D. ${ }^{3}$ \\ ${ }^{1}$ Lecturer, Department of Life Safety and Health-Saving Technologies, Institute of Physical Education, Sport and Tourism, Federal State Budgetary \\ Educational Institution of Higher Education «Petrozavodsk State University», Republic of Karelia, Petrozavodsk, Dzerzhinskoes Street, House 9 \\ ${ }^{2}$ Candidate of Historical Sciences, Associate Professor, Department of Life Safety and Health-Saving Technologies, Institute of Physical Education, \\ Sport and Tourism, Federal State Budgetary Educational Institution of Higher Education «Petrozavodsk State University», Republic of Karelia, \\ Petrozavodsk, Lesnaya Street, House 22 Apartment 7 \\ ${ }^{3}$ Deputy head of the Main Department, Main Department of EMERCOM in the Republic of Karelia, Petrozavodsk, Republic of Karelia, Petrozavodsk, \\ Pravda Street, House 25 a, Apartment 301
}

Received: 23/05/2020

Accepted: 27/09/2020

Published: 20/12/2020

\begin{abstract}
This article is devoted to the problem of using airmobile groups, the issues of evaluating their capabilities are considered, information is provided on the created airmobile group in the Republic of Karelia.
\end{abstract}

Keywords: Airmobile group, Equipment, Emergency, EMERCOM of Russia

\section{Introduction}

Fires in nature - the so-called landscape fires - pose a serious threat to the environment, economy and population. Depending on the place of origin, they are subdivided into forest, steppe, marsh, tundra, haze, savanna, steppe, reed, field and others. At its core, landscape fire is a spontaneously spreading combustion, as a result of which forests, shrubs, peat reserves and various types of vegetation that are in its path are destroyed. Despite the fact that $90 \%$ of landscape fires occur in connection with human activities, or because of their carelessness, most of them are classified as natural disasters. Landscape fires most often occur in the most "favorable" summer season for this, which is called the fire season. After the occurrence of a fire source, the development and spread of landscape fire begins. The continuously advancing combustion zone, on which the combustion of the main combustible material occurs with the maximum heat release density for a given fire, is called the edge of the fire. It distinguishes between external and internal boundaries (Sofronov \& Volokitina, 2002; Ryapolova, Mikhalev \& Zolotukhina, 2003). The inner edge of the edge faces the area covered by combustion, and the outer edge faces the area not covered by combustion. The part of the edge that propagates with the greatest speed is called the fire front, and the one moving in the opposite direction is called the rear. The portions of the moving edge between the front and rear of the fire are called flanks. In the presence of flammable combustible materials (for example, clumps of coniferous undergrowth), individual sections of the fire front move forward, forming protrusions (tongues, wedges), and in the presence of fire-resistant areas (hollows, clumps of fireresistant vegetation), the formation of depressions (pockets) is observed.

All forest fires are extremely dangerous, since by the time the fight against them begins, as a rule, they already have time to develop over a large area and there are not enough means of fighting. Particularly dangerous are large mass fires that occur in dry weather and whose total area can reach hundreds of thousands of hectares. At the same time, there is an immediate threat of destruction by fire of settlements and objects of the national economy (ONE) located in forests, as well as strong smoke and gas pollution of large settlements remote from forests (Kudrin \& Podrezov, 2006). The main cause of forest fires is reckless or illegal actions of the population. So, in Russia, more than $75 \%$ of forest fires arose through the fault of a person. Massive foci of forest fires occur mainly in areas adjacent to settlements and transport routes, primarily on the territory of the most fire-hazardous forest areas (young conifers, pine forests, peat bogs, etc.). Fire hazard zones located within a radius of 5-10 km from the borders of cities and towns occupy very significant forest areas. The main damaging factors of landscape fires are: high temperature, causing the ignition of everything that will be in the area of the fire; Smoke in large areas, irritating people and animals, and in some cases poisoning them with carbon monoxide; limiting visibility; frightening psychological impact on people. Fires in forests and peat bogs are characterized by rapid development, a high rate of propagation of the fire front and the creation of vast zones of gas contamination and smoke with dangerous concentrations of combustion products. In case of massive fires in peatlands and forests, people in the open air and in structures will be affected by the following damaging factors, hazardous fire factors (HFF): (a) direct exposure to fire; (b) high temperature of the gas environment; (c) heat radiation from the flame; and smoke and gas pollution in the area of the fire.

The danger of peat fires is aggravated by the fact that they burn not only the peat layer, but also the roots of the trees. The fire spreads at a speed of up to several meters per day. When the soil under the trees burns out, the latter fall randomly. The burning depth of peat is limited only by the level of groundwater or the underlying mineral soil. Peat fire is not afraid of precipitation due to the hydrophobicity of bituminous peat particles. In this case, moisture goes into the groundwater 
past the peat particles, and the peat continues to burn until the deposit is completely burnt out. As a result of the action of damaging factors (fire, sparks, an increase in the temperature of the environment), the destruction and damage of forests occurs, a threat to human life is created, industrial facilities and settlements are destroyed. A forest fire also causes a decrease in the growth of wood, worsens the composition of forests, soil conditions, increases windblows and windbreaks, increases the amount of dead wood, and leads to a massive spread of harmful insects. The average temperature of combustion of forest combustible materials is $500-900^{\circ} \mathrm{C}$. The combustion (smoldering) temperature of peat is $500^{\circ} \mathrm{C}$ (at a humidity of 10 $30 \%$ ), $300^{\circ} \mathrm{C}$ (at a humidity of $65 \%$ ). The height of the flame is determined by the type and strength of the fire, wind speed, edge width and has the following average values: for a ground fire - 0.05-3 m, for raised fires - 3-15 $\mathrm{m}$ (above the level of the stand). The depth of peat burning depends on the thickness of the peat layer, its moisture content and can be $0.25-3 \mathrm{~m}$. The parameters of the gas content of the environment within the edge of the fire are characterized by the following average values: volumetric concentration of carbon monoxide - $1.2 \%$, carbon dioxide $-4.5 \%$, oxygen $-12.5 \%$. Fires in the steppes are characterized by a very rapid development; the speed of fire propagation is especially affected by the wind speed. With high and dense grass cover, strong winds and dry weather, the speed of flame propagation through tall crops and grasses reaches $500-600 \mathrm{~m} / \mathrm{min}$. With sparse and low vegetation and in the absence of wind, fires spread at a speed of $10-15 \mathrm{~m} / \mathrm{min}$. Fires in the steppe, as well as on grain fields, are usually detected late, as a result, it covers large areas of several thousand hectares. In the process of spreading a fire, a so-called "fire storm" is often formed, which throws fire over long distances, overcoming artificial and natural barriers up to $12-15 \mathrm{~m}$ wide.

The main consequence of the impact of forest fires on settlements and ONE is the threat of their destruction. In this regard, the predicted parameters of the impact are: the time the fire front reaches the boundaries of the object, the possibility of transferring fire, and the ignition or loss of the properties of the object due to the impact of the HFF. The initial data for assessing the consequences of forest fires are: type and form of fire; type of combustible materials (nature of the planting); wind speed and direction; the speed of propagation of the fire front; parameters of damaging factors. The transition of a landscape fire to objects occurs in several ways: (a) due to the effect of heat radiation from the torch or the torch itself on the combustible materials of the object; (b) by spreading the combustion front to the ground cover (grass, construction waste, etc.); and (c) due to the throwing of sparks and burning smut on the site. The fire hazard of a forest is determined by the probability of the occurrence and spread of fires. It includes anthropogenic and natural fire hazard, as well as fire hazard due to weather conditions. Thus, in order to change the fire hazard of forests, it is necessary to influence any of its components. Since fire hazard due to weather conditions is an unregulated factor, the impact is possible only on the first two factors. Forests in regions with a significant population density and intensive human activities experience a great anthropogenic load, performing recreational functions, so there is a high probability of a high temperature source. Such forests primarily need a fire-fighting device, which is understood as a system of organizational, technical and silvicultural measures aimed at preventing forest fires, reducing the degree of fire hazard, increasing the fire resistance of forests, detecting fires at the beginning of their development and eliminating them. To increase the fire resistance of forests and reduce the degree of fire hazard, it is envisaged: cleaning forests from litter; regulation of the composition of forest stands; sanitary cuttings.
In addition to these measures, fire barriers are created in forests, that is, areas of the territory that prevent the spread and development of forest fires. Fire barriers specially created on the territory of the forest fund include: mineralized strips; fire breaks; screens; edges; ditches. In addition, all-natural barriers are taken into account, that is, rivers, lakes, rocky placers, swamps. Roads, paths, skid tracks, cleared glades, and power transmission lines are also used as fire barriers.

Fire-hazardous areas in forests of groups I and II, as well as in developed forests of group III, are divided into blocks of the first order with an area of 2 to 12 thousand hectares. Firewalls are the boundaries of these blocks. The coniferous massifs within the blocks are, in turn, divided into blocks of the second order with an area of 400 to 1600 hectares, delimited by additional or internal barriers. At the same time, the width of the internal barrier from hardwood is $60-100 \mathrm{~m}$, from coniferous - $200 \mathrm{~m}$, excluding the gap width. In coniferous barriers, rubbish, coniferous undergrowth is cleaned, branches are cut to a height of $1.52 .0 \mathrm{~m}$, mineralized strips are laid every 20-30 m. It is also recommended to divide large areas of coniferous crops and young stands in forests of green zones and forests of group I in areas of intensive farming into blocks with an area of 25 hectares. The width of the barrier with the road in the center is $30 \mathrm{~m}$. To protect against possible underground fires, fire ditches are arranged along the borders of peat bogs and in plantations on peat soils. The depth of the ditches is to the mineral layer or to the groundwater level. The width along the bottom of the ditch is $0.2-0.4 \mathrm{~m}$, the width along the top is $1.5-2.8 \mathrm{~m}$. In general, the approach to the fire-fighting arrangement of forest areas is determined by the "Guidelines for fire prevention in forests and the regulation of the work of forest fire services." However, the fundamental issues concerning the order of designing these measures, methods of analysis and making management decisions are not considered in them. The variety of forest areas, characterized by an extreme difference in natural, forest growth, forest pyrological conditions, does not allow using the same approaches to protecting them from forest fires. In the studies of V.V. Furyaev and L.P. Zlobina (2017), the principles and methods of increasing the fire resistance of both individual plantations and large forest areas are determined, which consist in regulating the factors that determine the degree of fire damage to forest stands. These include: reserves of combustible materials, the composition of the tree canopy, undergrowth, undergrowth, their structure and structure, the nature of the shrub cover. Scales for assessing the fire resistance of plantations using computer technology based on six factors are proposed: the composition of rocks, taking into account the admixture of deciduous (aspen, birch), the average diameter of the stand, admixture of deciduous trees in the undergrowth and undergrowth, the height of the undergrowth, the amount of undergrowth and the degree of litter.

The problem of protecting settlements and economic facilities from forest fires is also quite acute abroad. The growth of the urban population in the USA in previously inaccessible areas necessitates the development of means and methods of protection against the effects of wildfires. Here, three zones (lines of defense) are foreseen to protect against forest fires around households. Break lines are laid between the zones, making it difficult for the flame to advance. Within the zone, a fire-resistant plantation structure is formed by selecting tree species with an optimal crown height and distance between trees, and the following fire-prevention preventive measures are envisaged: cleaning up accumulations of ground-based combustible materials; cleaning branches; reduction of stocks of wood combustible materials; decrease in the total amount of vegetation; and increased moisture content in the leaves. A 
different approach to this problem is observed in France. It consists in identifying "risk zones" around which the means of active and preventive struggle should be concentrated, and their mapping. The analysis of the spatial distribution of fires depending on the causes of their occurrence and the identification of "risk zones" required the creation of a methodology that allows the use of information sources already available in cartography in the form of an automated cartographic information system. Such a system was created in France and uses mathematically processed data on forest fires. The use of the capabilities of a geographic information system (GIS) for building fire hazard maps for forest areas is considered in the work. In this case, the fire hazard is assessed taking into account maps characterizing the type of combustible materials, topography, area availability and meteorological data. Regression relationships are presented for calculating indices characterizing the flammability of vegetable combustible materials, the danger of human activity. When carrying out calculations, the topographic map of a given area is conventionally divided into cells measuring $50 \times 50 \mathrm{~m}$ (Fedorov \& Ryapolova, 2001). In practice, often only separate measures are taken to prevent forest fires (for example, laying mineralized strips). According to V.V. Furyaev and N.P. Kurbatsky (1972), mineralized strips $1.4 \mathrm{~m}$ wide have an efficiency of $62 \%$ for low and medium intensity ground fires; $2.8 \mathrm{~m}-88 \% ; 4.2 \mathrm{~m}-100 \%$. As you can see, a mineralized strip $1.4 \mathrm{~m}$ wide in $62 \%$ of cases prevents the spread of a ground fire with a flame height of $0.5-1.0 \mathrm{~m}$. prevention of the spread and development of ground forest fires in their other forms.

In accordance with the Guidelines for the design of fireprevention measures in forests, the pyrological properties of barriers are divided into 4 groups: practically incombustible fire barriers; fire barriers with a limited amount of combustible materials, insufficient to maintain intense combustion; fire barriers with the presence of combustible materials of low fire hazard; combined fire barriers. Such a classification makes it possible to rank the existing linear formations, but does not allow choosing the optimal forest growing conditions and technologies for creating new barriers (Gorbunov, 2009). As already noted, barriers on their own cannot ensure the prevention of the spread of a ground fire, and even more so its development in a top fire. To do this, it is necessary to take additional measures: increasing the width of the barriers, reducing the density and composition of conifers, undergrowth, young growth, regulating the admixture of deciduous species, etc. most contribute to its localization. In addition to the mineralized strips, it is recommended to create fire-prevention barriers, that is, wide forest strips, with the help of special measures brought to an incombustible state.

Recently, heads of districts and forestry enterprises have proposed to use fire breaks to protect settlements from forest fires. These are strips with felled stands and a road built on them. This event is recommended to be carried out to separate large homogeneous fire hazardous forest areas into separate ones. However, a strip of felled forest increases the turbulence of air flows, and in the event of a fire, it can increase its intensity and the range of transport of burning particles. At present, a system of measures is known to increase the fire resistance of pine young stands. It includes: clearing clearings, clearing and rehabilitating forest roads, creating protective mineralized belts, arranging fire reservoirs and entrances to them, creating fire-resistant belts, creating fire-resistant edges, regulating the admixture of deciduous species, regulating the density of stands, undergrowth and undergrowth, regulating stocks combustible materials under the plantation canopy, the formation of fire barriers and barriers. These activities can also be used in older forests. As a preventive measure in the
Mediterranean regions of France, it is proposed to use shrub cutting, which can reduce the mass of combustible material and prevent the spread of fire to the tops of the trees. However, this method is expensive and must be repeated every 3 years. Additionally, it is proposed to equip fire reservoirs. The division of the massifs into zones and the creation of forest plantations in the forms with the best fire resistance are envisaged.

Recently, such an event as artificial target burning of forest combustible materials has become increasingly important in our country and abroad. Studies have shown that exposure to fire greatly affects the continuity and duration of many natural processes. Dichenkov N.A. (2003) indicates that one of the effective fire-prevention measures is the use of controlled fire in the forest area. With the development of human economic activity, natural fire regimes have changed significantly, and at present, the restoration of the original regimes and the corresponding complexes of vegetation and fauna is quite problematic. However, if the system of purposeful, strategically thoughtful fire management develops, then it can gradually fulfill the same role in ecosystems as natural fire regimes. In this regard, the future of many species of forest fauna depends on the successful development of just such fire management systems. Preventive firefighting can be used not only to reduce stocks of forest fuels, but also as a means of managing forest fires. However, their implementation requires careful consideration of a large volume of meteorological, forest pyrological, topographic and other data.

With the increasing role of the anthropogenic factor, the fire rate of forests has increased significantly. As a result, an increase in unforested areas, the share of deciduous plantations of derived forest types, and a deterioration in conditions for the restoration of conifers began to appear more and more intensively.

In 1963, in the report of the Committee on Wild Fauna of the United States, for the first time, the principles of treating fires as a natural evolutionary factor in maintaining natural biodiversity and ecosystems in general were formulated. In the Everglades National Park in 1953, it was discovered that protected pine stands, in the absence of fires, are gradually turning into a deciduous forest and losing their associated endemic plant and bird species. In 1958, the first artificial burning of vegetation was undertaken in the Everglades to preserve certain types of natural communities. Similar processes are observed in the boreal forests of Finland. The number of forest fires has sharply decreased here in recent decades. As a result, spruce gradually becomes the dominant species, which leads to negative microecological changes, a decrease in the number and species diversity of animals, and the productivity of forest ecosystems decreases.

The US National Park Service abandoned its policy of unconditional fire control in 1967. The concept of ecosystem protection was adopted. A fire, as a natural phenomenon, can be allowed on the territory of a national park if it is under control, within the designated allotment and is important for the management of ecosystems and species. The main principles of the new policy were laid out in the Fire Management Guide. In Canada, fires have always played an important role in reforestation. They have formed the plant communities of modern Canadian landscapes. Fire suppression was confined to the southern most populated areas of the provinces, while fire control was limited in the Yukon and northern Canada. The areas of boreal forests, with their flat relief that does not prevent the spread of fire, have been exposed to large and numerous crown fires. The idea of prophylactic burning has received recognition in Russia, but the use of prophylactic burns has not yet received widespread use. Preventive burning of forest 
combustible materials under the forest canopy is a complex silvicultural activity aimed at using the positive role of fire in the forest (Bokadarov \& Polyakov, 2013).

\section{Materials and Methods}

One of the most serious problems in the fight against forest fires, directly affecting not only the protection of forest resources, but also ensuring the safety of people is the organization of fire protection of settlements that are subject to the threat of destruction when the fire passes from the forest to buildings (Chervonny, 1973). According to Rosleskhoz, in 2011 the area of forest fires was 1,636,203 hectares. Compared to similar indicators in 2010, the area covered by fire decreased by 470 thousand hectares, the number of forest fires decreased 1.6 times, and the area covered by crown fires - 4.5 times. According to the head of the forestry department Viktor Maslyakov, the damage caused by forest fires in 2011 amounted to more than 20 billion rubles, which is almost 6 times less than the same indicator for the last year. The largest number of forest fires was recorded in the Siberian and Far Eastern federal districts. $90 \%$ of the areas covered by fire fell on 11 constituent entities of the Russian Federation. These include the Republic of Sakha (Yakutia), Buryatia, Komi; Zabaikalsky, Krasnoyarsky, Khabarovsk Territories; Amur, Arkhangelsk, Irkutsk, Sverdlovsk regions and Khanty-Mansi Autonomous Okrug (Podrezov, 2004; Information and reference system "Forest fires, means and methods of combating them, 2008; Shchetinsky, 2011). In the zone of active forest protection, from 10 to 30 thousand forest fires are registered annually, covering an area of 0.5 to 2.1 million hectares. The number of fires per 1 million hectares of the Russian forest fund is several times less, and the average area of one fire is several times larger than in Europe and North America.

As observations show (Shchetinsky, 2011;Valendik, 1990), the main organizational reasons contributing to the spread of forest fires are: untimely fire detection (20\% of fires are detected at the end of the day or the next day); untimely start of extinguishing ( $15 \%$ of fires start extinguishing at the end of the day or the next day); insufficient amount of forces and means directed to extinguishing; non-professional management of the extinguishing organization. In this regard, tough centralized actions on the part of forestry authorities are needed to control fire prevention and compliance with fire safety rules in forests, monitor fire conditions, promptly assess the situation and coordinate the work of different departments to extinguish forest fires. The characteristic features of the spatio-temporal structure of forest fire, which are of fundamental importance for the organization of their protection and fire protection of settlements, is a sharp variation in the number and area of forest fires by regions of the country and periods of fire hazardous seasons. From 50 to $90 \%$ of the annual forest area covered by fire falls on 3-4 regions of the country with extreme weather conditions. The area of extremely flammable zones, where a significant part of fires gets out of the control of the security system and takes the character of a natural disaster, makes up only a few percent of the forest fund every year. Moreover, up to $95 \%$ of the entire area covered by fire falls on large forest fires, the number of which does not exceed $5 \%$ of the total number of fires in forests (Podrezov, 2004; Information and reference system "Forest fires, means and methods of combating them, 2008). With the annual area of clear felling from 1.5 to 2.0 million hectares and the same rate of forestforming processes in burned-out areas and clearings, the annual areas of forest stand perishing from fire should be 3.04.0 million hectares. Taking into account the forest cultivation work carried out in the clearings and measures to promote natural regeneration, as well as the presence of significant areas of burned areas in the northern regions of the country with the worst conditions for reforestation, the actual rates of forest formation processes on them can be 2-3 times lower than on clearings. Even in this case, the annual area of forest stands dying from fire should be at least 1.0 million hectares (Information and reference system "Forest fires, means and methods of combating them, 2008).

Emergency statistics show that in Russia the share of wildfires (forest, steppe, peat, landscape fires, as well as their possible combinations) and the emergencies caused by them is approximately $24 \%$ of the total number of emergencies (Podrezov, 2004; Shchetinsky, 2011). Due to the insufficient effectiveness of the currently existing measures to protect settlements from forest fires, even if the requirements of regulatory documents in the field of fire safety are strictly observed, a fundamentally new comprehensive approach to the design of fire barriers is needed, taking into account the peculiarities of the location of each individual settlement. The modern organization of extinguishing landscape fires is a complex system that unites participants in operational and tactical actions and firefighting equipment, tools and equipment (Krektunov \& Gainullina, 2012). A landscape fire is a fire that engulfs various components of a geographic landscape (GOST 17.6.1.01-83). The main task of organizing extinguishing landscape fires is to minimize the process of performing certain operational and tactical actions of the airmobile group while simultaneously obtaining high operational indicators, preserving the life and health of personnel. Achieving this goal is possible on a scientific basis. Airmobile grouping of the EMERCOM of Russia is a group of specially trained and equipped forces and means of the EMERCOM of Russia, which, depending on the classification of an emergency or fire, includes the necessary management bodies and units of the Ministry of Emergencies and is delivered to the disaster area using aviation, aviation technologies, and also others modes of transport to solve the tasks assigned to it (Guidelines for the creation, equipment and procedure for the use of airmobile groups of territorial bodies of the EMERCOM of Russia). Extinguishing a landscape fire is currently all types of work aimed at its localization and elimination in the shortest possible time. The key factors that the command and control of the airmobile group evaluates (the so-called extinguishing leadership triangle) are: (a) resources involved (quantity, quality, enough or not); (b) information about the fire (must be timely and complete); and (c) management (must be continuous and efficient).

To improve the effective management of the airmobile grouping of the Ministry of Emergency Situations, one should have statistical information on the consequences of managerial decisions made, on the structure of time spent by managers and subordinates. The necessary data can be obtained in the course of carrying out one-time surveys, including questionnaires of employees, taking photographs and self-photographing of working hours, using the method of instant observations. The choice of the method of obtaining information, methods of its processing and analysis is individual. The indicators of the use of working time will give an idea of the effectiveness of the management of the airborne group. In general, working time is understood as the length of time during which an employee actually performs work, and is a measure of assessing various labor costs. The working time of an airmobile group is recorded in man-hours. The structure of working time expenditure during the conduct and organization of emergency rescue operations of the airmobile group on the ground, the reasons for its irrational use must be analyzed in the Main Directorate and conclusions should be drawn for making managerial decisions 
to improve the use of working time and as a result increase labor productivity. In order to identify the reasons for the loss of working time or its irrational use, one-time statistical surveys are carried out. The information obtained will help to carry out the correlation of controllability standards and production rates, including many other issues related to the functioning of the airmobile group as intended. As is known from practice, the level of labor productivity depends on many factors. When analyzing the labor productivity of employees in the airmobile group, one of the primary tasks is to assess the influence of factors on the change in this indicator, which in turn allows obtaining material for making managerial decisions on planning to increase the productivity of emergency rescue operations. The productivity of rescue operations, especially when separated from a permanent location, is influenced by various factors: technical and technological; socio-economic; natural and climatic; organizational; structural; and motivating employees. The way the factors influence the performance of rescue operations is different. Some of them can be objective, since their action does not directly depend on the activities of employees, others are subjective, and their quantitative characteristics are amenable to regulation by the employee himself.

The productivity of employees when extinguishing landscape fires is influenced by such a factor as the method of work. To this end, provide for specially organized observations on the study of methods of performing work, which will allow you to choose the best methods and teach these methods to other employees, which in turn will increase productivity. In any given emergency or landscape fire, developing a strategy to improve the performance of rescue operations involves quantifying the extent to which each factor affects employee productivity. Directly in management, it is possible to study the dependence of the average output on the qualifications of an employee, technical equipment, organization of emergency rescue operations and other factors. In order to solve such problems, it is proposed to apply correlation-regression analysis. In the scientific literature on statistics, labor productivity has a widespread model of the following type:

$\mathrm{Y}=\mathrm{abcd}$,

where abcd - conventional designation of factors: a - average hourly output; $\mathrm{b}$ - the average duration of the working day (shift), h; c - average payroll number of employees; $\mathrm{d}$ - the share of employees in the number of personnel of the main activity. The improvement of the system of operational-tactical actions of subunits must be carried out through their detailed analysis and design. Designing the organization of the use of an airmobile group should be based on a quantitative assessment and be reduced to the choice of the optimal option, which cannot be done without building a mathematical model and using the methods of applied mathematics. In relation to the optimal variant, the norms for extinguishing forest fires should be calculated. The correct organization of extinguishing landscape fires is designed to ensure a well-coordinated combination of actions of firefighters, mobile fire extinguishing equipment, fire equipment and tools within the established regulations for performing certain actions (Shchetinsky, 2002). First of all, it should be noted that extinguishing a landscape fire is a complex of management decisions and operational-tactical actions aimed at eliminating combustion, ensuring the safety of people and saving material assets. In operation, the process of extinguishing a fire is conditionally divided into two periods: the first - before the moment of localization, the second - after this moment, i.e. when the fire is stopped, it is limited to some extent. Taken together, all measures to eliminate steppe fires can be divided into several main categories. The first of these includes the socalled reconnaissance actions. The second is the localization of the source of fire, the third is the elimination of the fire. The last category, in turn, includes the guarding of the danger zone. Localization often consists of two phases. First of all, further spread of fire is prevented. This is achieved by direct and direct exposure to the flame edge. The second phase, in turn, includes the laying of the so-called barrage structures. Sand strips, dug ditches, and so on can act as such means. In addition, it is necessary to carry out processing of the peripheral areas of the fire in order to prevent as much as possible the possibility of renewed fire spread. It is important to remember that the definition of "localized fire" is understood to mean one around which there are barrier strips or other means that provide complete confidence that the flame cannot re-ignite.

The so-called fire extinguishing is the elimination of fires that could remain in the territory captured by the fire. It is important to eliminate everything, even the smallest and most inconspicuous petals of the flame. Firefighting is designed to prevent the resumption of combustion processes. Due to the fact that in a steppe fire, the vegetation layer burns out completely - the possibility of re-ignition of already burned out areas is completely excluded, there is no need to guard the entire area covered by the fire. Therefore, guarding is carried out only along the border of the fire. The duration of the stage under consideration must be determined based on the predicted and current weather conditions. The main reserves for increasing the efficiency of the airmobile grouping lie in the use of reliable fire-fighting tools and equipment for their intended purpose, as well as in the elimination of losses of working time, which is largely determined by the level of organization of fire extinguishing.

\section{Results and Discussion}

At present, the introduction of promising methods based on a larger, but accurate quantitative analysis will make it possible to plan the effective work and well-coordinated interaction of the units that make up the airmobile group. With regard to the optimal option for extinguishing landscape fires on the territory of the Republic of Karelia, it is necessary to calculate the norms for the process of extinguishing forest fires, since this is more relevant, as can be seen from the statistical data on wildfires over the past 25 years given in Table 1. Emergency rescue operations to protect settlements from landscape fires are complex processes that consist of the following stages of actions of an airmobile group:

Receiving and processing messages about a landscape fire (coordinates of the occurrence of a thermal point);

- Collection of the airmobile group - departure and following to the place of the landscape fire (coordinates of the occurrence of the thermal point);

- Reconnaissance of the focus of a landscape fire;

- Deployment of forces and assets;

- Localization of combustion in the zone of landscape fire;

- Supply of fire extinguishing agents (elimination of combustion);

- Organization of special works (protection of buildings from possible fires, disconnecting power lines by cutting electrical wires, organizing fire communications, plowing the edge of a fire, lighting the unit's workplace, lifting (lowering) to a height, evacuating people and material values, etc.);

- Collection and transportation to the place of permanent deployment. 
Table 1: Statistics on wildfires over the past 25 years

\begin{tabular}{|c|c|c|c|c|c|c|c|c|c|c|c|}
\hline \multirow{2}{*}{ 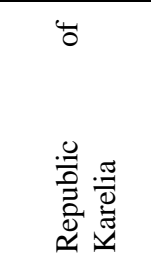 } & \multirow{2}{*}{$\begin{array}{l}\text { Period of } \\
\text { passage of } \\
\text { natural } \\
\text { fires } \\
\text { (from - } \\
\text { to __ ) }\end{array}$} & \multicolumn{3}{|c|}{ Number of fires } & \multicolumn{3}{|c|}{ Suffered } & \multicolumn{2}{|c|}{$\begin{array}{l}\text { Destroyed by } \\
\text { fire }\end{array}$} & \multirow[b]{2}{*}{$\begin{array}{l}\text { Material } \\
\text { damage } \\
\text { (million } \\
\text { rubles) }\end{array}$} & \multirow[b]{2}{*}{ Note } \\
\hline & & 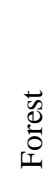 & $\stackrel{\widetilde{\varpi}}{\tilde{2}}$ & 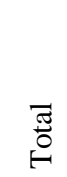 & 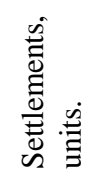 & 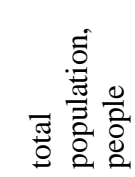 & 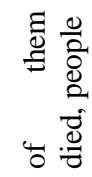 & 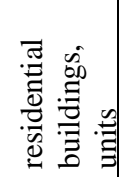 & 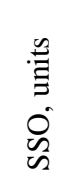 & & \\
\hline 1995-2019 & $\begin{array}{l}\text { May- } \\
\text { September }\end{array}$ & $\begin{array}{l}11 \\
46 \\
7\end{array}$ & 0 & $\begin{array}{l}114 \\
67\end{array}$ & 0 & 0 & 0 & 0 & 0 & 4253,71 & $\begin{array}{l}\text { Damage } \\
\text { for RK }\end{array}$ \\
\hline
\end{tabular}

In accordance with the regulatory documents of the EMERCOM of Russia and the order of the Main Directorate dated January 29, 2016 No. 30 "On ensuring the readiness of the airmobile grouping of the Main Directorate of the EMERCOM of Russia in the Republic of Karelia to liquidate emergencies and fires", the composition of the forces and means of the airmobile group for extinguishing fires and emergency situations. The use of the airmobile group is planned according to the Plan for the Prevention and Elimination of Emergency Situations during the period of natural fires in the Republic of Karelia in 2020, shown in Figure 1. An increase in operational and tactical capabilities for extinguishing landscape fires with an airmobile group assumes the systematic introduction of the principles of efficiency and sufficiency of the use of forces and means of the Main Directorate of the Ministry of Emergencies of Russia in the Republic of Karelia in the organization of firefighting, as well as the introduction of advanced experience. When fighting landscape fires, it is recommended to use the following technical means.

1) Tillage tools used for laying protective and supporting mineralized strips: single-body plows (PKB-75, PBN-75); PLN-135 strip forest plow; plow-trencher PKLN-500A; forest cutter FLU-0.8; bulldozer installation D-271; horse plow PG-25.

2) Machines used for laying protective mineralized strips: bulldozer D-533; strip laying machine PF-1.

3) Tools used for ditching: trencher LKN-600.

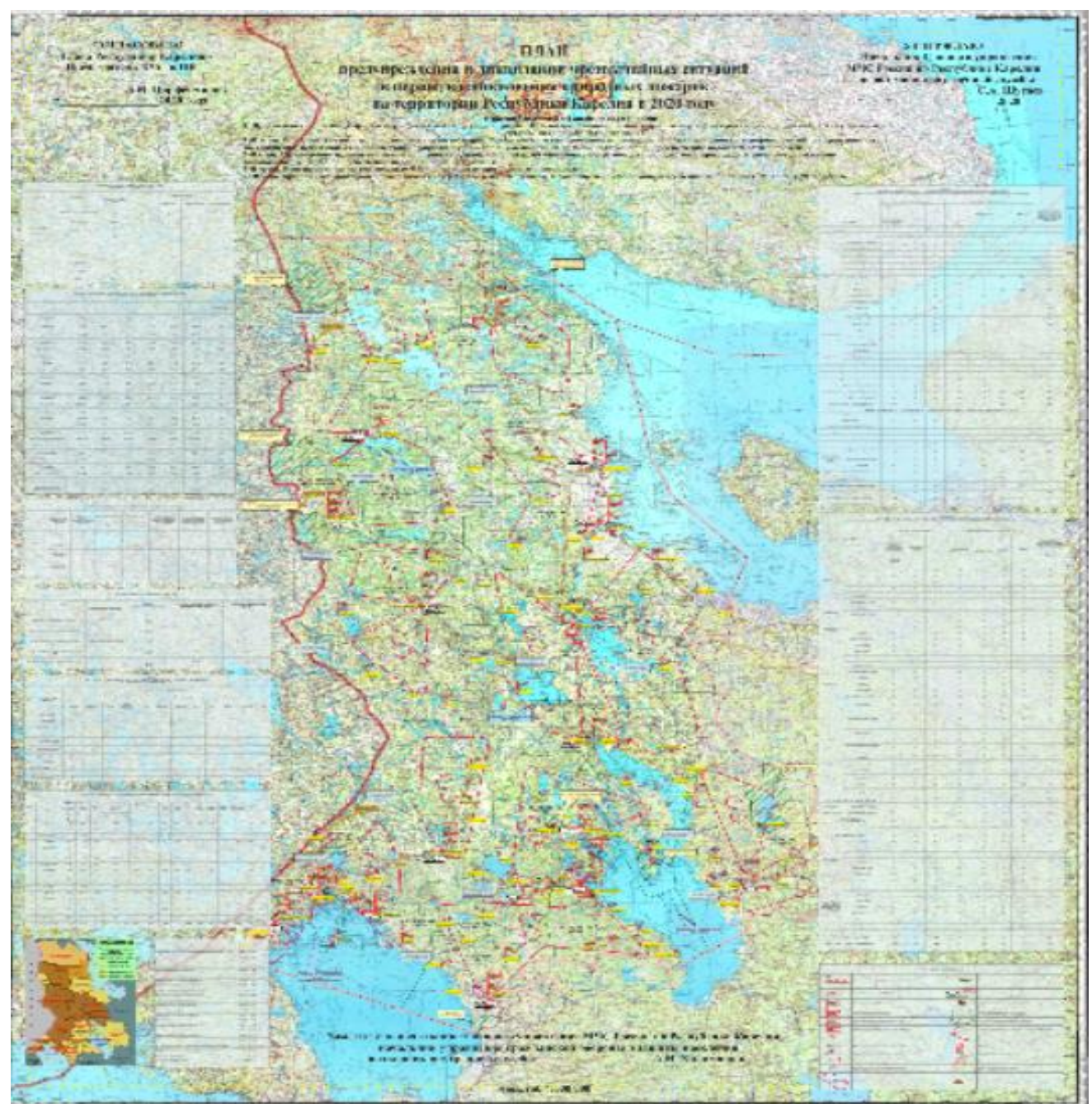

Figure 1: Plan for the prevention and elimination of emergency situations during the period of natural fires on the territory of the Republic of Karelia in 
4) Machines and equipment for extinguishing fires with water: fire-fighting tankers of various types; fire-fighting motor pumps (portable type MP-600, MP-600A, MP-800B, MPN-800/80, trailed type MP-1600, MP-16, MPP-1600, "GEYSER"); fire pumps MNPV-90/300, MMP-2400S, mounted type NSHN-600M, fire nozzles (high-pressure spray gun with hose reel SRVD-2/400-60, manual highpressure fireman barrel RSKU-20VD, fire monitors and manual firemen barrels with ejection of a foaming agent, for example, a manual combined universal fireman RSKU50Ae, monitors with oscillators, for example LS-60 (40.50) Uo).

5) Special forest fire units for extinguishing fires with water and fire extinguishing chemicals: ATsL-147 - forest fire tank truck on the chassis of the GAZ-66 vehicle; ML-1/0.75 - small-sized portable fire-fighting motor-pump; forest tractor fire tank TsPLT-2; MDP-0.2 motor-pump, light forest fire, floating type; MLV-1, MLV-2/12, MLV22/0.25 - high-pressure forest fire motor pumps; forest firefighting set of DSP equipment, soft container for water delivery to forest fire sites RDV-1500, firefighting boat LS52A; VPPL-149 is a forest fire all-terrain vehicle.

6) Special forest fire units of complex action: timber tanker ATsL-3 (66) -147; forest fire unit TLP-55; forest firefighting all-terrain vehicle VPL-149; TLP-4 forest fire tractor; (T-150K) -177 - forest fire unit based on the T$150 \mathrm{~K}$ tractor, tracked fire engine GPM-10, forest fire tractor MSN-10 PM, fire engine on tracked chassis LHT100A-12.

7) Knapsack fire extinguishers-sprayers: knapsack forest sprayer RLO-M; knapsack fire extinguisher ORM-1; chemical sprayer ORX-3; backpack pneumatic fire extinguisher ROOP-4A; backpack sprayer OP; OLU-16 universal forest fire extinguisher (for water, solutions of fire-extinguishing salts, emulsions, foaming agents and fire-extinguishing powders).

8) Peat trunks (TS-1, TS-2).

9) Soil guns: GT-3 - tractor forest fire ground gun (based on T150K); ALF-10 - forest fire milling unit (based on MTZ$82)$.

10) Installation for receiving and supplying gas-filled foam by the compression method UGNP.

11) Firefighting pumping stations (for example, PNS-100 (43114) -50VR).

12) Fire pump and hose complexes ("Shkval", "Potok").

13) Fire trucks based on MT-LB chassis:

- A floating fire truck based on the MT-LBu chassis;

- Multipurpose floating forest fire and tilling machine based on MT-LB chassis;

- Floating pump and hose machine based on the MT-LBu chassis.

14) Two-link tracked snow and swamp vehicle TTM4902ASM with rescue, fire and medical equipment.

15) TTM 3930ASM wheeled all-terrain vehicle, manufactured on the chassis of the TTM 3930 wheeled all-terrain vehicle (rescue vehicle based on the ASM-KPP wheeled snow and swamp vehicle).

16) Light fire module "Ermak".

17) Air blower - sprayer EFCO 2090.

18) Aviation technology:

- Aircraft IL-76P (forest fire aircraft with two removable tanks with a total weight of 40 tons), amphibious aircraft Be-200ChS, $\mathrm{AN}-2$; AN-2V; AN-26P (forest fire aircraft with two external tanks with a total volume of 4 tons), AN-32P;

- Helicopters MI-6, MI-8 with suspended pouring devices; modular helicopter complex MVK-2 for external suspension of the MI-17 helicopter (MI-8MTV, KA-32); modular helicopter complex MVK-8 for external suspension of the MI-26 helicopter; suspended containers P1-00 with a volume of 1000 liters; helicopter discharge complex KSV-1 for the external suspension of the MI-8 helicopter;

- Unmanned aerial vehicles for monitoring the forest fire situation.

When fighting landscape fires, aviation performs the following tasks:

- Direct extinguishing of fires by dumping extinguishing liquid on the hotbeds;

- Patrolling the area, reconnaissance of fires, search and rescue of victims;

- Creation of air control points for forces and fire extinguishing means;

- Transportation of forces and means of fire extinguishing and evacuation of victims;

- Ensuring the conduct of ASDNR (delivery of small-sized cargo, ensuring the advancement of operational reconnaissance groups, monitoring the implementation of the tasks assigned to them by firefighting forces, relaying communications, cellular communications with rescuers, commands for controlling robotic systems, etc.).

19) Robotic complexes.

As the experience of extinguishing forest peat fires in the period of 2010-2014 in the Moscow, Vladimir, Nizhny Novgorod, Ryazan, Tver regions, Bashkiria and Udmurtia has shown, robotic systems are effective when conducting operations in difficult terrain, where the deployment of conventional wheeled and tracked vehicles is significantly difficult. In addition, their use is advisable when it is necessary to protect industrial facilities with the risk of radiation-chemical and high-explosive fragmentation in the event of a fire spreading to protected areas located in the forest zone. In the course of work on the elimination of these forest-peat fires, the following new samples of fire-fighting robotics were tested.

- Remotely controlled fire extinguishing installation LUF-60;

- Mobile robotic fire extinguishing systems EL-4 and EL-10;

- Mobile installation robotic gas-water extinguishing (MRUGVT);

- Robotic complex "KEDR" consisting of two machines for extinguishing grassland forest and peat fires.

Based on the work, the following results were obtained for the considered RTC. Mobile remote-controlled fire extinguishing installation LUF-60. Installation LUF-60 allows you to create an intense flow of water and transport it over considerable distances in the air flow. Using these qualities, ground fires were extinguished in a forest area along a newly formed clearing - a mineralized strip. The water was supplied from a fire tank truck with a water supply of 2400 liters, the total total duration of the discrete supply was $150 \mathrm{~s}$, while the estimated water flow was $16 \mathrm{l} / \mathrm{s}$. Water was supplied through the central shaft in the operating fan mode (50\% of the power), the elevation angle of the shaft was 10-40 degrees, which made it possible to change the effective distance of water supply from 10 to $45 \mathrm{~m}$. As a result, a 35x60 m surface was treated, on which everything visible open foci of combustion were extinguished, no swelling of foci of combustion was observed. Hidden burning areas (hemp, tree hollows, etc.) could not be completely extinguished. The entire surface in the installation area was saturated with water, which significantly reduced the likelihood of a secondary fire. Mobile robotic fire extinguishing systems EL-4 and EL-10 allow to carry out work on barriers in forest blockages, as well as to extinguish fires using water foam. In the course of the work carried out, the possibility of creating passages in the area of forest clearing with simultaneous firefighting was shown. The water consumption for the EL-4 was $20 \mathrm{l} / \mathrm{s}$, which was supplied to a piece of wood 
in the combat area, which is covered by the EL-4. The range of water supply in the sector of water supply with an angle of 90 degrees was $35 \mathrm{~m}$. It is advisable to use additives to the OTV.

It is advisable to use a mobile robotic gas-water extinguishing unit (MRGWT) to prevent the development of forest fires by irrigating a forest. To increase the efficiency of this method, it is necessary to use additives that increase the fire resistance of wood. Carrying out work with the installation of MRUGVT on a real fire seems inappropriate due to the insufficient amount of water for the operation of MRUGVT in the fire zone. Particular attention should be paid in terms of solving the problems under consideration to the developed and successfully tested in the elimination of forest peat fires in the Tver region in 2014, the robotic fire complex "KEDR". The complex is located on the chassis of the MTLB-u floating lightly armored tracked carrier. The complex includes the "KEDR-HP" pump and hose machine and the "KEDR-P" fire extinguishing machine. Depending on the specific conditions, both vehicles can be controlled remotely or by the crew. The design of the pump and tube machine allows you to take water from natural sources in difficult terrain using a submersible pump, while the machine itself can be on the surface of the reservoir or, if it is impossible to enter the water, by lowering the pump into the water using a lifting device. The fire extinguishing machine provides extinguishing fires both with the help of a fire monitor and liquidation of ground fires using a special irrigation installation. Based on the results of work on fire extinguishing of forests and peat bogs, the following proposals and recommendations were developed. When extinguishing forest fires in order to successfully eliminate high-intensity fires, including raised ones, it is advisable to use an RTK with water supply through a hose line from an external source, including from a hose car. In contrast to fires at industrial installations, the specificity of a forest fire is characterized by the variability of the direction of the flame front, depending on natural conditions. In this case, the ability to maneuver the RTK is significantly limited, which can lead to their death. In such conditions, it is advisable to use not a single RTK, but in tandem with another in order to ensure their interaction for successful evacuation from the fire source by supplying a fire-extinguishing agent to cool the RTK and block its escape routes. The peat bogs were extinguished with the help of the KEDR robotic system with feeding the hose line with a pump with a capacity of $60 \mathrm{l} / \mathrm{s}$. With the help of the complex, it is possible to extinguish and shed an area of about 10 hectares of peat bog within three days. The complex can also be used as a pumping station from reservoirs, to which it is impossible to send vehicles on wheels. It was installed at the end of the hose line to increase the pressure and supply water to the barrels; at the same time, 5-6 barrels operated from the pump with a pressure in the hose line after the pump from 4.5 to 7 atmospheres. With the help of this machine, about 6.5 hectares were extinguished and shed. The results obtained allow us to conclude about the effective operation of the MRKP for the formation of passages in the conditions of forest fires and extinguishing minor foci of combustion (ground fires).

20) Stationary, flexible, soft fire tanks.

21) Personal protective equipment (including a fire suit of a volunteer PKD "Chance").

22) Considering that the closest to the fires are agricultural enterprises that have at their disposal equipment that can be used to eliminate forest and peat fires. The following machines are especially often used:

- Semitrailer to the DT-75 tractor peat machine (PTM);

- Fire tanks with a capacity of 5000 \# 100001 together with MTZ tractors; serve to extinguish fires in places that are inaccessible for other equipment;
- Watering machines (PM-13OB, etc.); used independently to extinguish ground fires or to supply water;

- Spreaders of liquid fertilizers (RZhU, RZhT, RZh); can be used to supply water to the fire site; especially effective in fire extinguishing RZhT-8 and RZhT-16.

Currently, RZhT is equipped with special nozzles for connecting pressure fire hoses.

It is also advisable to note that in addressing the issues of extinguishing forest-peat fires, it is effective to use field trunk pipelines (PMT), which are equipped with the Armed Forces of the Russian Federation.

\section{Conclusions}

Due to the insufficient effectiveness of the currently existing measures to protect settlements from forest fires, even if the requirements of regulatory documents in the field of fire safety are strictly observed, a fundamentally new comprehensive approach to the design of fire barriers is needed, taking into account the peculiarities of the location of each individual settlement.

Thus, after conducting the research, we can conclude that the increase in operational and tactical capabilities for extinguishing landscape fires with an airmobile group presupposes the systematic implementation of the principles of efficiency and sufficiency of the use of forces and means of the Main Directorate of the Ministry of Emergencies of Russia in the Republic of Karelia in the organization of firefighting, as well as the introduction of advanced experience.

\section{Ethical issue}

Authors are aware of, and comply with, best practice in publication ethics specifically with regard to authorship (avoidance of guest authorship), dual submission, manipulation of figures, competing interests and compliance with policies on research ethics. Authors adhere to publication requirements that submitted work is original and has not been published elsewhere in any language.

\section{Competing interests}

The authors declare that there is no conflict of interest that would prejudice the impartiality of this scientific work.

\section{Authors' contribution}

All authors of this study have a complete contribution for data collection, data analyses and manuscript writing.

\section{References}

1. GOST 17.6.1.01-83: Nature protection. Protection and protection of forests. Terms and definitions. Retrieved from http://www.normative_reference_dictionary.academic.ru

2. Guidelines for the creation, equipment and procedure for the use of airmobile groups of territorial bodies of the EMERCOM of Russia (approved on 05/30/2014 by the Chief military expert E.N. Chizhikov). Retrieved from http://www.consultant.ru

3. Podrezov, Yu.V. (2004). Technology of fighting natural fires. Firefighting and rescue equipment, no 2, pp. 34-42.

4. Information and reference system "Forest fires, means and methods of combating them." (2008). Krasnoyarsk.

5. Shchetinsky, E.A. (2011). Sputnik of the head of extinguishing forest fires. Moscow.

6. Valendik, E.N. (1990). Struggle with large forest fires. Novosibirsk: Science. Sib. Det.

7. Krektunov, A.A., \& Gainullina, E.V. (2012). The main problems of organizing fire protection of settlements in the prevention and suppression of forest fires. Problems of ensuring safety in the elimination of the consequences of emergency situations, no $1, \mathrm{pp}$. $77-79$. 
8. Furyaev, V.V., Tsvetkov, P.A., Furyaev, I.V., \& Zlobina, L.P. (2017). Conditions for the occurrence and spread of fires in the forest regions of the Krasnoyarsk Territory. Conifers of the boreal zone, no 35 (1-2), pp. 66-74.

9. Furyaev, V.V. \& Kurbatsky, N.P. (1972). The effectiveness of protective mineralized strips in young pine forests. Questions of forest pyrology. Krasnoyarsk: ILiD SO AN SSSR.

10. Dichenkov, N.A. (2003). Forest protection. Russian Federation. Federal Forestry Service.

11. Bokadarov, S.A., \& Polyakov, R.Yu. (2013). Ways to reduce the fire hazard of forests. Modern technologies for civil defense and emergency response, no 1 (1 (4)), pp. 107-116.

12. Gorbunov, S.V. (2009). Means of individual and collective protection in emergency situations. Novogorsk: AGZ.

13. Fedorov, E.N. \& Ryapolova, L.M. (2001). Geoinformation systems and technologies in the practice of fighting forest fires and their consequences. Forest and steppe fires: occurrence, spread, extinguishing and ecological consequences. Tomsk-Irkutsk.

14. Sofronov, M.A. \& Volokitina, A.V. (2002). About the fireprevention device of the forest territory. Lesn. hozyayistvo, no 5, pp. $45-47$.

15. Ryapolova, L.M., Mikhalev, Yu.A. \& Zolotukhina, L.P. (2003). Fire-prevention arrangement of forests adjacent to settlements and other objects in the forest. Forest protection from fires reforestation and forest management. Krasnoyarsk: IPC KSTU.

16. Kudrin, A.Yu. \& Podrezov, Yu.V. (2006). Analysis of modern means and methods of fighting natural fires Technologies of civil safety, no 4 (10), pp. 27-32.

17. Shchetinsky, E.A. (2002). Extinguishing forest fires: A guide for forest firefighters. Moscow: VNIILM.

18. Chervonny, M.G. (1973). Protection of forests from fires. Moscow: Forest industry. 